(c)

I SUPPLY CHAIN, OPERAÇÕES E LOGÍSTICA • SERVIÇO COMPLETO

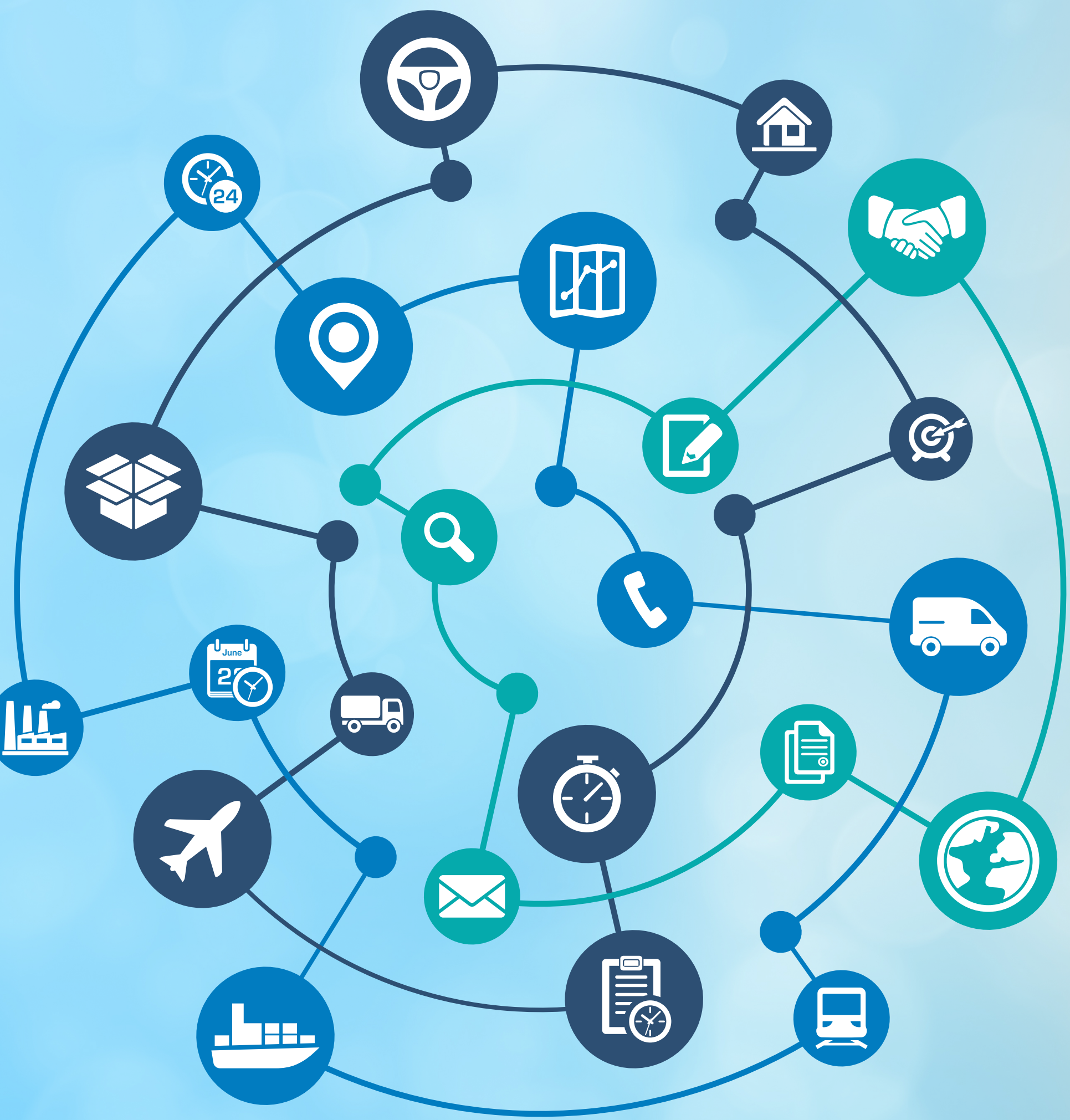




\section{SERVIÇO COMPLETO}

| POR FÁBIO CAMPOS TESCARI E EDUARDO ANTONIO SCALESE JUNIOR

\section{O customer service, que antes só cuidava das reclamações dos clientes, agora enfrenta o desafio de conectar a área comercial à cadeia produtiva e, assim, proporcionar atendimento flexível e integral.}

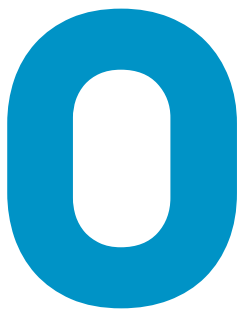

mercado tem exigido de seus fornecedores cada vez mais flexibilidade, customização, lotes menores e prazos de entrega curtos, com os objetivos de minimizar estoques e aprimorar as previsões de vendas. Para melhorar a eficiência nesses pré-requisitos, as empresas estão redesenhando suas conexões internas e adicionando serviços à sua oferta de produtos, a chamada "servitização".

A "servitização" engloba diversas categorias de serviços, entre elas:

1. Serviços integrados aos produtos, como a atualização automática de um software;

2. Serviços que ampliam o escopo da oferta do produto, como um fornecedor de máquinas que faz a gestão de estoques de peças sobressalentes para agilizar a manutenção das máquinas pelo cliente;

3. Serviços relacionados à distribuição física, como transporte e armazenagem, agregados à venda de grãos ou combustíveis.

A definição do serviço depende do tipo de produto. Se o produto que está sendo transacionado é uma commodity, os fornecedores geralmente buscam facilitar e baratear o acesso dos clientes aos produtos. A Vale, por exemplo, chegou a investir em supernavios para atender de forma mais competitiva ao mercado chinês de

\section{Entregar o serviço que o cliente quiser demanda um esforço enorme de relacionamento do customer service com diversas áreas e prestadores de serviços em bases quase personalizadas.}

minério de ferro. Por sua vez, produtos mais sensíveis, como microprocessadores e flores, requerem embalagens mais elaboradas para acondicionamento e transporte.

Um dos principais desafios gerenciais da "servitização" é definir como se dá a interface entre os produtos fabricados e os serviços oferecidos. A gestão do serviço ao cliente, ou customer service, é que faz esse elo entre as áreas comercial e de supply chain. Com a necessidade cada vez maior de lançar novos produtos, diversificar, atrair o consumidor final, reduzir estoques, ser assertivo nas previsões de vendas em um mercado nem sempre previsível, atentar para questões ambientais e sociais e melhorar resultados financeiros, a área de customer service tem cada 
vez mais relevância nos processos internos e externos das empresas fornecedoras. A principal responsabilidade dessa área é garantir que as expectativas dos clientes sejam plenamente satisfeitas, visto que os processos de venda se iniciam e terminam neles.

O desenvolvimento de novas tecnologias também exige que as organizações estejam mais próximas dos seus clientes, que, muitas vezes, optam por - ou são levados a - resolver seus problemas de atendimento sozinhos. Em pesquisa publicada recentemente pela Harvard Business Review, $81 \%$ dos entrevistados afirmaram que procuram solucionar inconvenientes sem contatar os prestadores de serviços. Monitorar o resultado dessas ações também é responsabilidade do customer service. Além disso, se por um lado essa mudança de hábitos contribui para reduzir custos, por outro isso significa que as empresas têm de estar preparadas para lidar com problemas mais complexos, os quais não puderam ser resolvidos apenas com a intervenção voluntária do cliente.

Outra tendência é de as empresas-clientes desenvolverem medições de desempenho de seus fornecedores em relação aos serviços. No mercado de cosméticos, por exemplo, os ciclos entre o recebimento das matérias-primas e a venda do produto final têm sido cada vez mais curtos, por volta de 15 a 20 dias. O relacionamento entre o fabricante de cosmético e seus fornecedores torna-se quase instantâneo, dada a necessidade de atender a indicadores como: redução de estoques de matérias-primas e produtos acabados, melhoria do capital de giro e recebimento de produtos e insumos dentro do prazo. Assim, a área de customer service dos fornecedores deve estabelecer ferramentas e processos alinhados às necessidades da área de planejamento de demanda do cliente.

\section{EVOLUÇÃO DAS ATRIBUIÇÕES DO CUSTOMER SERVICE}

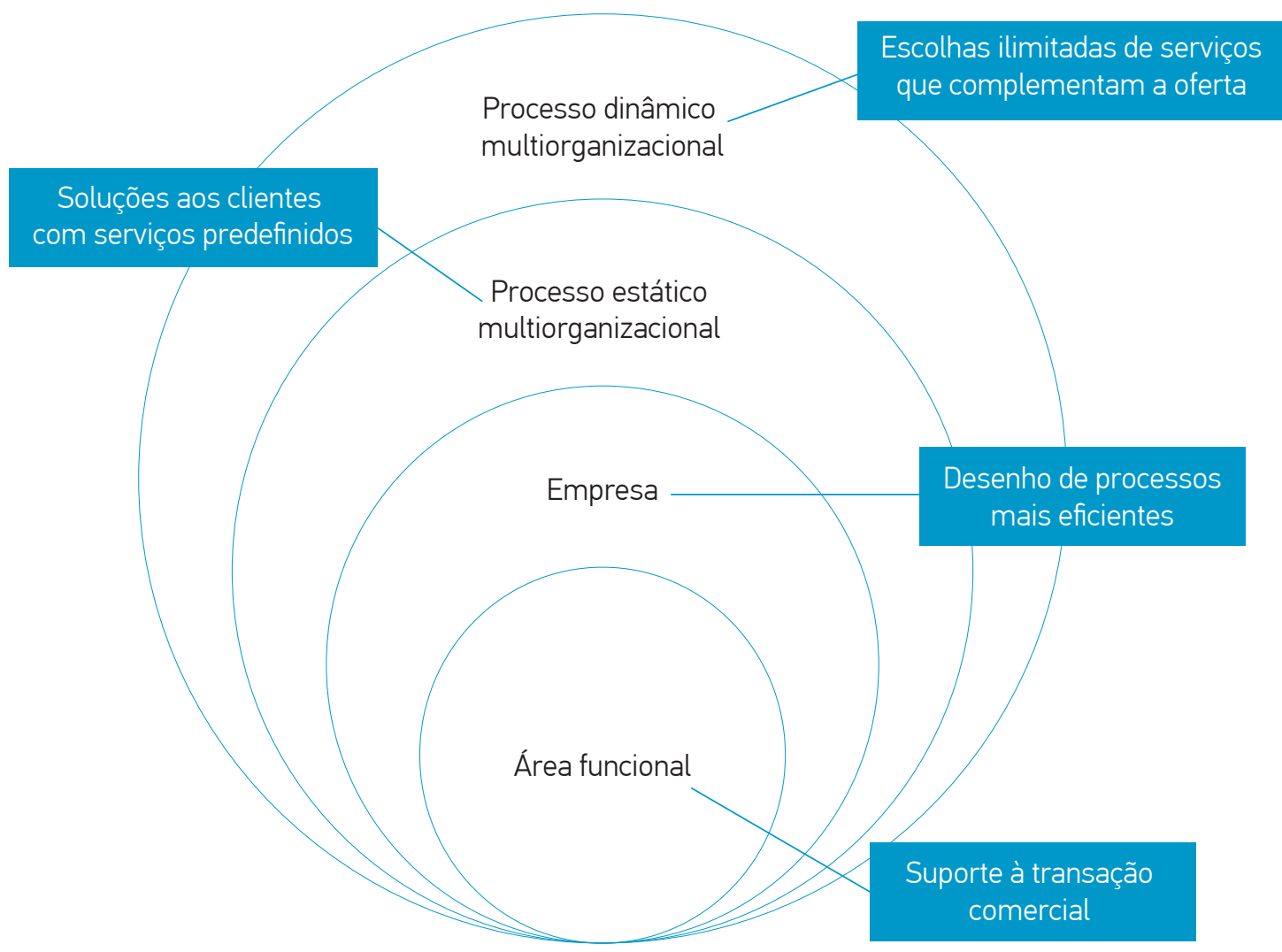




\section{As empresas que conseguirem conectar o comercial com o supply chain por meio do customer service, com indicadores alinhados às necessidades dos clientes, terão vantagem competitiva expressiva em relação à concorrência.}

\section{A DINÂMICA DO CUSTOMER SERVICE}

Há três décadas, a área de customer service promovia os relacionamentos entre áreas internas da organização apenas para responder reativamente a reclamações de clientes. Atualmente, sua função é pró-ativa, baseada no conhecimento da cadeia produtiva e na compreensão das demandas dos consumidores.

Quando o consumidor final busca um produto, muitas vezes desiste se este não estiver disponível. Para garantir o correto abastecimento das lojas e depósitos de canais de venda digitais e evitar perda de vendas, o fabricante deve colaborar com seus fornecedores, compartilhando informações de previsão de demanda e revendo prazos de recebimento de matérias-primas. Para ter um processo eficiente, é essencial que o fornecedor entenda como a empresa-cliente determina suas demandas, qual é o perfil dos seus consumidores, quais são os seus canais de distribuição e como ela dispara seu processo produtivo.

Em geral, a área de planejamento de clientes recebe a informação sobre a demanda já definida pelas áreas de vendas e marketing. $\mathrm{O}$ fato é que o simples repasse desses dados aos fornecedores não garante o atendimento pleno do mercado, seja em prazo, seja em quantidade. Para isso, é necessário envolver o customer service dos fornecedores, de modo que ambas as partes compreendam a dinâmica de produção e abastecimento de toda a cadeia de suprimentos, além das características do mercado consumidor final.

A área de customer service dos fornecedores também precisa compartilhar com a área de vendas da empresa-cliente a responsabilidade sobre a previsão de pedidos para determinado período (quinzenal, mensal, trimestral etc.). Os fornecedores, às vezes, identificam potenciais novos volumes de vendas que os clientes não percebem, pois estes podem estar preocupados com outros indicadores, como redução de estoques. Ou seja, mesmo que aparentemente as empresas-clientes tenham domínio do mercado em que atuam, há casos em que o fornecedor é quem alerta sobre a possibilidade de demandas adicionais.

Além disso, a área de compras da empresa-cliente deve conhecer profundamente os ciclos produtivos dos fornecedores e compartilhar essas informações tanto com o customer service quanto com o comercial, melhorando os processos de planejamento.

A área de customer service está inserida, portanto, entre as áreas comercial, de compras e de planejamento. Mostrase como uma potencial ferramenta estratégica, contribuindo não só para melhorar o alinhamento da cadeia de suprimentos como um todo, mas também para afinar processos que possibilitem ganhos adicionais na satisfação dos clientes.

\section{OS DESAFIOS DO CUSTOMER SERVICE}

As atividades desempenhadas pelo customer service têm elevado grau de complexidade por conta das suas interfaces com diversos stakeholders. Por ser responsável por atender às demandas dos clientes e por conduzir os processos internos de forma mais eficiente, o customer service precisa ganhar mais relevância do que tem hoje na maioria dos fornecedores.

A implementação integrada de indicadores para as áreas comercial, customer service e supply chain também é fundamental para a melhoria do atendimento aos clientes - com desdobramentos para cada área. Por exemplo, o customer service deve ser medido pelo on time in full (OTIF), que mede a eficácia das entregas quanto à data combinada (on time) e à quantidade exata (in full), enquanto o comercial deve ser medido pelo faturamento e o supply chain pelo custo de aquisição e pelo OTIF de fornecedores. Entretanto, esses modelos de gestão podem variar entre regiões e empresas.

Outro desafio relevante para o customer service é expandir seu espectro de atuação em relação às expectativas dos clientes, conforme mostra a ilustração Evolução das atribuições do customer service. Seu escopo, inicialmente 


\section{O PASSO A PASSO PARA UMA GESTÃO EFICAZ DE CUSTOMER SERVICE}

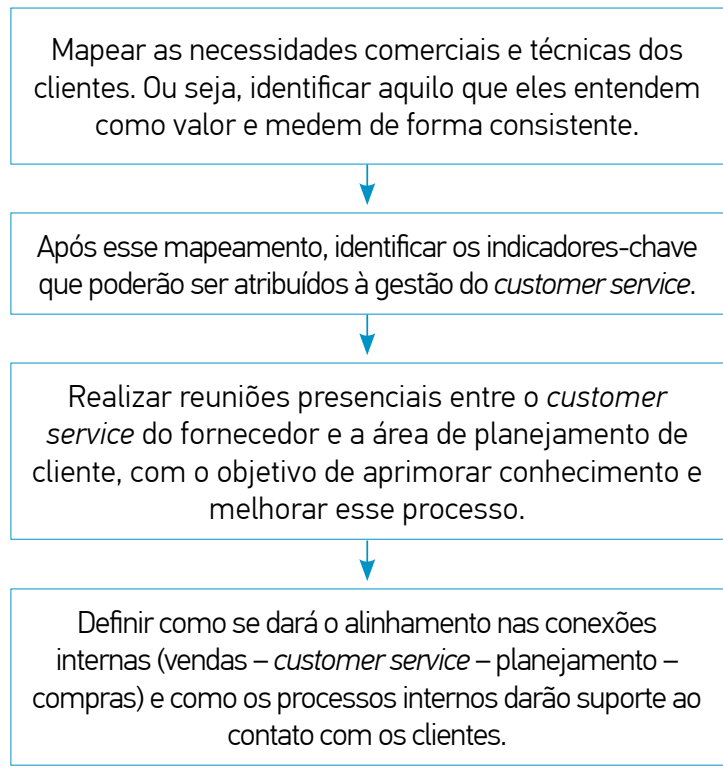

funcional - dando suporte a transações isoladas -, evoluiu para uma abordagem de eficiência dos processos de atendimento aos clientes, como na identificação de melhorias na comunicação entre as áreas por meio da implantação de sistemas integrados de gestão (o Enterprise Resource Planning, que em português significa Sistema de Gestão Empresarial - ERP). Depois, a atuação de customer service expandiu-se para a entrega de soluções previamente definidas, como serviços de gestão de estoques de seus produtos armazenados pelos clientes, o que poderia incluir até os volumes de produtos importados de outras fontes. Ocorre que a entrega de soluções, por si só, não garante mais diferenciação. A área de customer service deve desenvolver um portfólio maior de serviços, propiciando aos clientes um conjunto de escolhas amplas que possam complementar a oferta. Seria o caso, por exemplo, de um fornecedor de equipamentos oferecer múltiplos formatos de instalação e manutenção (própria, terceirizada, incluída ou não no preço, feitas por diferentes prestadores de serviços etc.) à escolha da empresa-cliente.

Por fim, um grande desafio para as organizações no que se refere ao fluxo de atividades de customer service é a mudança comportamental. Não é trivial transformar sua gestão para que utilize informações de mercado de forma estruturada, disciplinada e compartilhada, com a

\section{PONTOS DE ATENÇÃO}

- $\quad 0$ cliente deve ser informado sobre o escopo do trabalho da área de customer service.

- Os indicadores devem ser definidos em comum acordo entre cliente e fornecedor.

- $\quad 0$ customer service deve integrar-se com as outras áreas de contato do cliente.

- O customer service deve ter conhecimento tanto do negócio do cliente como da sua dinâmica na elaboração de forecasts e cálculos de demanda, o que, em determinados mercados, pode ser muito complexo.

- $\quad$ o customer service deve entender da cadeia fornecedora por meio de um estreito contato com a área de compras, assim como conhecer o processo produtivo de sua organização.

- A gestão do customer service exige disciplina, foco, transparência e, acima de tudo, o envolvimento da alta administração para garantir o correto alinhamento interno.

\section{Customer service mostra-se como uma ferramenta estratégica para melhorar o alinhamento da cadeia de suprimentos e obter ganhos na satisfação dos clientes.}

tecnologia adequada. As empresas que conectarem o comercial com o supply chain por meio do customer service, definindo claramente papéis e indicadores e trabalhando de forma compartilhada, terão vantagem competitiva expressiva em relação à concorrência. Isso passará a ser valor agregado ao produto.

FÁBIO CAMPOS TESCARI > Pesquisador e professor colaborador do Centro de Excelência em Logística e Supply Chain (GVcelog) da FGV EAESP > fabio.tescari@fgv.br EDUARDO ANTONIO SCALESE JUNIOR > Executivo e professor colaborador do Mestrado Profissional em Gestão para a Competitividade com ênfase em Gestão de Supply Chain da FGV EAESP > eduardo.scalese@uol.com.br
} 


\section{Primeira revista acadêmica do Brasil especializada na publicação de casos de ensino.}

GVcasos é um periódico eletrônico da FGV/EAESP, lançada por meio de parceria entre a RAE-publicações e o CEDEA - Centro de Desenvolvimento do Ensino e da Aprendizagem.

A missão da GVcasos é fomentar a produção e o uso de casos de ensino em Administração, contribuindo para a disseminação do uso de casos como metodologia de ensino e aprendizagem em nível de graduação, pós-graduação, especialização e educação continuada.

Desde seu lançamento em 2010, a GVcasos publicou mais de sessenta casos em diferentes áreas de Administração: estratégia, marketing, recursos humanos, responsabilidade social e contabilidade. Professores distribuídos em mais de duzentas e cinquenta instituições de ensino localizadas no Brasil e no exterior.

O conteúdo da GVcasos é composto de duas partes:

a) Conteúdo gratuito com acesso livre: casos de ensino nas diversas áreas da Administração, disponíveis para o público em geral.

b) Conteúdo gratuito e restrito a professores: formado pelas notas de ensino dos casos publicados.

A submissão de casos de ensino, acompanhados das respectivas notas de ensino, é aberta a colaboradores de modo geral e deve ser feita pelo sistema online da

\section{GVcasos.}

\section{Acesse para ler e submeter casos de ensino:} FGV.BR/GVCASOS

\section{Central de Relacionamento}

Contatos: + 55(11) 3799-7999 ou 3799-7778

Fax: + 55(11) 3799-7871

gvcasos@fgv.br 